\title{
O ENSINO INFORMAL DE CIÊNCIAS NO AMBIENTE DE POSTOS DE SAÚDE: UMA ANALOGIA COM O AMBIENTE MUSEOTÉCNICO À LUZ DA TEORIA SÓCIO-HISTÓRICA DE VIGOTSKI
}

\author{
Julio César Castilho Razera* \\ Carla Santana Santos Souza**
}

RESUMO: O objetivo da pesquisa foi delinear a ocorrência do ensino informal

*Doutor em Educação para a Ciência pela UNESP.

Professor Adjunto do de Ciências no ambiente de postos de saúde, especialmente por intermédio de cartazes e folhetos expostos nesses locais. Foi feita uma analogia com o que acontece em museus e centros de Ciências, levando em consideração a teoria sócio-histórica de Vigotski. Postos de saúde são instituições que não têm como principais objetivos a divulgação científica e o ensino de Ciências, mas constatamos que podem oferecer importantes situações de ensino informal para a área da saúde. Acreditamos que aspectos teóricos e práticos já observados em estudos de museus e centros de Ciências podem ser úteis para maior compreensão e melhor aproveitamento desse potencial. Palavras-chave: Alfabetização Científica. Saúde. Cidadania.

THE INFORMAL TEACHING OF SCIENCE IN A HEALTH CENTER: AN ANALOGY WITH THE MUSEOGRAPHICAL ENVIRONMENT UNDER THE LIGHT OF VIGOTSKI'S SOCIAL AND HISTORICAL THEORY

ABSTRACT: This research was aimed at delineate the occurrence of informal teaching of Science in health centers. Through posters and leaflets displayed in these locations, as well as interviews with users, we managed to build an analogy with Science museums and centers under the light of Vigotski's social and historical theory. Scientific dissemination and Science teaching are not the primary objectives of health centers, but the results obtained, indicate that these environments can provide important informal learning situations, especially when it comes to the Health field. Theoretical and practical aspects that have already been observed in studies of museums and Science centers can help us understand the use of this potential.

Keywords: Scientific Literacy. Health. Citizenship. 


\section{INTRODUÇÃO}

O problema da pesquisa que relatamos surgiu durante uma discussão sobre as possibilidades e os limites dos museus para o ensino informal de Ciências ou para a alfabetização científica. No transcorrer desse debate, fomos construindo um exercício mental de comparação com outras instituições de características diferentes dos museus, mas que teriam potencial semelhante para esse tipo de ensino de Ciências. A teoria sócio-histórica de Vigotski deu suporte à implementação de nossa investigação sobre o assunto.

Em seus estudos, Gaspar (1993) afirma que só se pode conceber uma instituição de educação informal voltada para o ensino de Ciências se houver respostas válidas a questões como a viabilidade e a relevância de uma abordagem superficial, ou seja, se essa abordagem pode ser feita de forma produtiva num ambiente informal. Além disso, deve-se levar em consideração as implicações do ensino informal para o formal e vice-versa. Ainda que possam ocorrer de formas distintas e graus variados, pareceu-nos haver respostas positivas a essas indagações para ambientes além dos museus e centros de Ciências. Entre as outras possibilidades de ambientes, incluímos os postos de saúde, que são instituições governamentais distribuídas por quase todos os municípios brasileiros e que atendem uma parcela da população que, em muitos casos, nunca frequentou uma escola ou que já não a frequenta por um período significativo.

Não temos pretensões ingênuas de ignorar as diferenças de complexidade estrutural e contextual dessas duas instituições - museus, ou centros de Ciências, e postos de saúde. Da mesma forma como fez Marandino (2001) ao traçar as interfaces entre museu e escola, buscamos nossos objetivos na preservação de dois universos particulares, "onde as relações sociais se processam de forma diferenciada”, pois sabemos que cada uma das instituições tem uma lógica própria.

Museus e postos de saúde são duas instituições que se diferem nas suas funções, nos seus objetivos, nos seus públicos-alvo, mas que nem por isso deixam de apresentar alguns pontos de convergência sobre o ensino informal. Ambos, por exemplo, apresentam elementos que potencializam a popularização científica e a aprendizagem em Ciências.

Os elementos dos museus, que provocam interatividade dos tipos hands on, mind on ou heart on ${ }^{1}$ (WAGENSBERG, 2005) com os visitantes, já são conhecidos e discutidos em pesquisas. No caso dos postos de saúde, existem os cartazes afixados nas paredes ou murais, e os folhetos disponíveis que trazem conteúdo científico dirigido ao público usuário do local, com potencial de ensino informal a ser investigado. Afinal, esses objetos presentes (portanto, efetivos) nos postos de saúde seriam eficientes na apresentação do conteúdo e eficazes na produção de efeito ou resultado desejado para a popularização ou divulgação científica e para o ensino informal de Ciências? Quais seriam os aspectos limitantes e potenciais nesse processo?

O conceito de ensino informal utilizado neste trabalho foi escolhido com base nas afinidades entre o que entendemos ocorrer nos postos de saúde e as 
características desse tipo de educação apresentadas por alguns autores: uma educação que não contempla, necessariamente, a estrutura dos currículos tradicionais; não oferece graus ou diplomas; não possui caráter obrigatório de qualquer natureza; e não se destina exclusivamente aos estudantes, mas também ao público em geral (COOMBS; AHMED, 1973; COOMBS, 1986; GASPAR, 1993); uma educação que qualquer pessoa adquire e por meio da qual acumula conhecimentos com a experiência diária em casa, no trabalho, no lazer ou em algum outro ambiente de seu cotidiano (BIANCONI; CARUSO, 2005); uma educação que os indivíduos aprendem durante o processo de socialização, ou seja, com a família, no bairro, no clube, com os amigos etc.; uma educação que é carregada de valores e culturas próprias, de pertencimento e sentimentos herdados (GOHN, 2006).

Depois de problematizada, a pesquisa foi implementada com o objetivo de delinear a ocorrência de possibilidades e entraves do ensino informal de Ciências no ambiente de postos de saúde, especialmente por intermédio de cartazes e folhetos expostos ou disponíveis. Foi feita uma analogia com museus e centros de Ciências à luz da teoria sócio-histórica de Vigotski. O enfoque investigado privilegiou a perspectiva do usuário, que é quem vivencia e interage com esse tipo de ambiente, expressando-se como agente diretamente envolvido no processo de ensino informal.

Por fim, destacamos a importância desta pesquisa levando em consideração a relevância que a educação em Ciências tem para a consolidação de cidadania na sociedade atual. Acreditamos que a educação não se restringe a ações isoladas apenas dos espaços escolares, pois o exercício consciente de responsabilidade cidadã só é possível se os indivíduos possuírem uma cultura científica de base, para que possam compreender e intervir no mundo em que vivem. Dessa forma, a aprendizagem não pode ser vista como um processo que se desenvolve exclusivamente na escola, mas ao longo da vida dos indivíduos em outros espaços institucionais. Espaços extraescolares devem contribuir, cada qual com suas especificidades, para uma educação mais ampla e atualizada, mais acessível e democrática (RODRIGUES; MARTINS, 2005).

\section{BREVE EXPOSIĈ̣̃O DA BASE TEÓRICA}

A analogia que estabelecemos entre os ambientes museotécnicos e os dos postos de saúde em relação ao ensino informal de Ciências teve como parâmetro a teoria sócio-histórica de Vigotski, aproveitando-se de pressupostos apresentados por Gaspar (1993), que fez dessa teoria um referencial de sustentação e de melhor compreensão sobre o processo de ensino informal em ambientes de museus e centros de Ciências. "Aspectos dessa teoria [de Vigotski], a nosso ver, fornecem as indicações que buscamos em relação ao processo ensino-aprendizagem em museus e centros de ciências" (p. 57).

Gaspar (1993, p. 72) apresenta três indicações básicas que uma teoria deve oferecer aos museus e centros de Ciências: i) "a possibilidade da ocorrência efetiva 
do processo ensino-aprendizagem num ambiente informal"; ii) "a viabilidade de um ensino informal em ciências"; iii) "a forma de interação entre esse ensino informal de ciências e o seu ensino formal". Para o autor, à luz da teoria de Vigotski é possível compreender melhor essas questões.

Sobre a efetividade da aprendizagem em museus ou centros de Ciências (primeira indicação), podemos dizer que a condição necessária passa pelas interações sociais entre seus visitantes ou entre monitores e visitantes. "A condição suficiente é que essas interações se dirijam às zonas de desenvolvimento proximal de seus participantes" (GASPAR, 1993, p. 72).

De acordo com Vigotski (2001, p. 328), “a zona de desenvolvimento imediato tem, para a dinâmica do desenvolvimento intelectual e do aproveitamento, mais importância que o nível atual de desenvolvimento”. As investigações de Vigotski demonstraram que "aquilo que está na zona de desenvolvimento imediato em um estágio de certa idade realiza-se e passa ao nível do desenvolvimento atual em uma segunda fase” (p. 331). Em outras palavras, o que se faz em colaboração hoje poderá ser feito sozinho amanhã.

$\mathrm{Na}$ analogia empreendida neste trabalho, partimos do pressuposto que interações sociais ocorrem nos postos de saúde: sejam elas interpessoais (relação sujeito-sujeito), entre pessoas e os cartazes e/ou folhetos informativos (relação sujeito-objeto) ou entre pessoas e o ambiente (relação sujeito-contexto). Pudemos, então, tecer aproximações entre os dados da pesquisa e os aspectos teóricos dessas interações no viés das relações entre ação mediada e zona de desenvolvimento imediato dos usuários.

Assim como apresenta Colinvaux (2005), recorremos à noção de ação mediada de Wertsch (1999), que está na perspectiva vigotskiana, ou seja, uma ação mediada que busca integrar aspectos diversos da ação humana, articulando cultura e ação do sujeito por meio da categoria de ferramentas culturais ${ }^{3}$.

Com base nessas ideias, as interações ocorridas nos postos de saúde devem ser analisadas partindo do pressuposto de que esses ambientes podem ser considerados - assim como os museus - instituições culturais, pois oferecem ferramentas culturais (por exemplo, cartazes e folhetos) que, por sua vez, oferecem certas possibilidades de ação.

Sobre a viabilidade de um ensino informal de Ciências (segunda indicação) nos postos de saúde, também podemos encontrar aproximações possíveis nos pressupostos de Vigotski, assim como fez Gaspar (1993) em seus estudos sobre museus: "as exibições de um museu ou centro de ciências [aqui entendemos que postos de saúde entram neste contexto] podem ser entendidas como uma forma de ampliar o repertório de pseudoconceitos do visitante, que poderão vir a se tornar conceitos verdadeiros [...] tanto na escola como fora dela" (p. 79).

Para Vigotski (2001, p.170), "momento central, que tem todos os fundamentos para ser considerado causa decorrente do amadurecimento de conceitos, é o emprego específico da palavra, o emprego funcional do signo como meio de formação de conceitos". No processo de desenvolvimento - do estágio de 
pseudoconceitos para o estágio de conceitos -, a comunicação estabelecida por intermédio das palavras é relevante. No estágio dos pseudoconceitos, as palavras inseridas no repertório do indivíduo possibilitam, mesmo que de forma não consciente, que ele se comunique. E com o tempo, faz com que ele adquira o significado, na transição do pseudoconceito para o conceito. Portanto, podemos dizer que os cartazes e folhetos disponíveis nos postos de saúde, assim como outros elementos contextuais, no mínimo servem a esse fim, ou seja, ampliam o repertório e as possibilidades de mediação semiótica entre os usuários.

Do que se apresenta anteriormente, vimos que a viabilidade do ensino informal perpassa a aquisição ou a ampliação de significados (mediação semiótica), fato que permite melhor qualidade na comunicação e, nessa ampliação dos pseudoconceitos, aumenta a possibilidade da transformação deles em conceitos verdadeiros. Nesse caso, mesmo que os usuários de postos de saúde não tenham mais a oportunidade de frequentarem o ensino formal, ainda haverá benefícios na melhoria da qualidade da comunicação no aumento de possibilidade de atingirem a fase dos conceitos científicos, por outros meios, fora da escola.

Sobre a última indicação apresentada quanto à compreensão da forma como a educação informal interage com a educação formal, sobretudo no que se refere ao ensino de Ciências, Gaspar (1993, p. 81) afirma que "ela está implícita essencialmente na compreensão da relação entre os conceitos espontâneos e científicos”. E complementa: "na medida em que os conceitos espontâneos são fruto da educação informal e os conceitos científicos da educação formal, a interação entre essas duas formas de educação depende basicamente da interação entre esses conceitos".

Segundo Vigotski (2001), é científico todo o conhecimento de origem formal. São conhecimentos sistemáticos, hierárquicos e apreendidos num sistema de relações. Ao contrário, os conhecimentos espontâneos não são sistemáticos, mas baseiam-se em situações particulares e adquiridos da experiência cotidiana. "A diferença crucial entre essas duas categorias de conhecimentos é a presença ou a ausência de um sistema" (GASPAR; MONTEIRO, 2005). Apesar de Vigotski (2001) classificar como científicos todos os conceitos aprendidos na educação formal, e como espontâneos todos os conceitos originados da aprendizagem informal, ele destaca a unicidade cognitiva do processo de aquisição desses conceitos:

O desenvolvimento dos conceitos espontâneos e científicos [...] são processos intimamente interligados, que exercem influências um sobre o outro [...], trata-se do desenvolvimento de um processo único de formação de conceitos, que se realiza sob diferentes condições internas e externas mas continua indiviso por sua natureza e não se constitui da luta, do conflito e do antagonismo de duas formas de pensamento que desde o início se excluem (VIGOTSKI, 2001, p. 261).

Diante do que foi brevemente exposto, podemos dizer que a teoria de Vigotski se coaduna com os pressupostos de compreensão do processo de ensino informal em museus, postos de saúde ou outros ambientes, pois se configura na tese de que a aprendizagem precede o desenvolvimento. Isso nos faz pensar 
nas possibilidades ou desperdícios dessas possibilidades quando se leva em consideração a tese vigotskiana para subsidiar projetos de ambientes potenciais de ensino informal.

A aprendizagem só é boa quando está à frente do desenvolvimento. Neste caso, ela motiva e desencadeia para a vida toda uma série de funções que se encontravam em fase de amadurecimento e na zona de desenvolvimento imediato. É nisto que consiste o papel principal da aprendizagem no desenvolvimento (VIGOTSKI, 2001, p. 334).

Em suma, a tese de Vigotski - de que a aprendizagem precede o desenvolvimento - e a busca dos indicativos de possibilidade, viabilidade e formas de interação entre ensino informal e formal deram rumos a este trabalho. O delineamento traçado para a ocorrência de aprendizagem no ambiente dos postos de saúde, por meio dos objetos impressos disponíveis e de seu contexto, pôs em pauta os seguintes aspectos: i) as interações sociais; ii) o direcionamento das interações em relação à zona de desenvolvimento imediato; iii) a mediação semiótica; e iv) a relação de complementaridade entre ensino informal e formal.

\section{PROCEDIMENTOS METODOLÓGICOS}

A pesquisa foi realizada entre os meses de janeiro e maio de 2007, no maior e mais movimentado posto de saúde de um município de aproximadamente 170 mil habitantes, no interior de uma região socialmente carente do Brasil. Inicialmente, a diretora da instituição foi informada sobre as pretensões da pesquisa. Depois de formalizada a autorização, foram realizadas observações exploratórias e anotações prévias do ambiente e dos usuários em relação aos cartazes afixados e folhetos disponíveis no local. Em seguida, realizaram-se entrevistas semiestruturadas com usuários do local, escolhidos aleatoriamente, e receptivos em contribuir com a coleta de dados. Nessa abordagem aleatória aos sujeitos, mesmo depois de explicados os motivos da entrevista, houve um número significativo de resistências e não aceitação em participar, que foram justificadas em decorrência ao analfabetismo: "Se eu não sei a leitura, como é que vou fazer isso?" (fala de usuário não entrevistado). Para esses casos não houve insistência, pois a participação dos sujeitos deveria ser totalmente espontânea.

Efetivamente, foram realizadas 20 entrevistas gravadas em áudio; um número considerado suficiente pela qualidade dos dados obtidos e pelos propósitos da pesquisa, que não teve intenções pautadas em estatísticas ou no caráter dedutivo ou generalizante, mas no delineamento da ocorrência de um evento (o ensino informal), num determinado ambiente (posto de saúde), para fins comparativos com a ocorrência em museus ou centros de Ciências e sob a perspectiva de uma base teórica. Na primeira fase da entrevista, os usuários responderam questões gerais, entre outras questões, sobre os hábitos de leitura, de percepção de aprendizagem 
e de entendimento dos cartazes e folhetos informativos disponíveis no local, sem, no entanto, especificar ou apontar nenhum desses objetos. $\mathrm{Na}$ segunda fase, foram mostrados três cartazes ${ }^{4}$ aos usuários (figura 1). Para complementação dos dados sobre os hábitos dos usuários, também foram coletadas informações orais de um funcionário que trabalhava diretamente no atendimento ao público.

Figura 1: Cartazes sobre rubéola (frente e verso), sarampo (frente e verso) e dengue
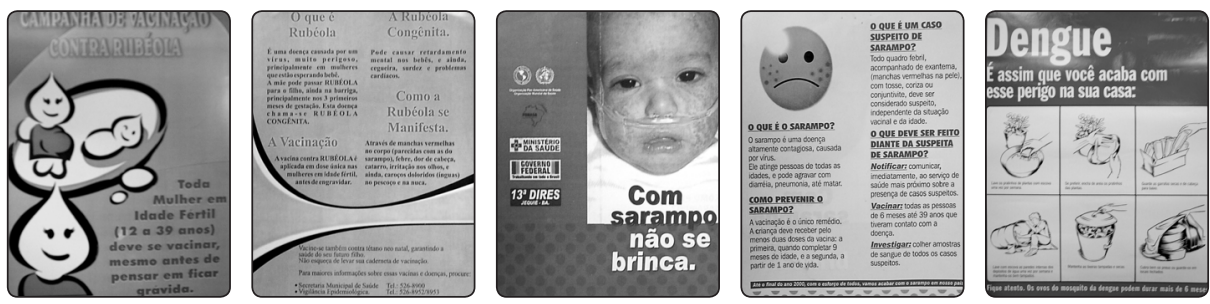

\section{PERFIL DO AMBIENTE E SUA IMPORTÂNCIA CONTEXTUAL NO ENSINO INFORMAL}

O posto de saúde analisado durante a pesquisa, assim como ocorre em outros ambientes desse tipo, afixa e expõe cartazes e folhetos informativos com conteúdos diversos da área de saúde, produzidos por órgãos governamentais da esfera federal e/ou estadual. Em geral, os usuários não manifestam o hábito de tirar dúvidas ou perguntar aos funcionários sobre os conteúdos desses materiais: "Raramente aparece alguém perguntando alguma coisa", informou o funcionário de atendimento ao público. Não há um trabalho específico e sistematizado de explicação sobre os conteúdos dos materiais expostos, interferindo nas possibilidades de favorecimento do ensino informal. Alguns relatos apresentaram indícios de haver um desejo, explícito ou implícito, dos sujeitos-usuários, de que mudanças poderiam ser empreendidas nesse sentido, a fim de melhor usufruir o ambiente: "Eu não leio, mas para as pessoas que sabe ler eu acho que transmite as informações. Mas eu acho que não adianta só a gente ver as figuras ali, eu acho que deveria ter um funcionário para explicar" (U11); "Eu acho assim... mostrar mais, ser mais aberto na questão de mostrar, de falar, sobre as doenças... os médicos, as enfermeiras, explicar mais quando as mães vêm vacinar seus filhos... as enfermeiras explicar sobre os cartazes" (U18); "Na minha opinião, teria que ter aqui sempre nas sextas-feiras um congresso... todas as sextas com uma doença diferente, ensinando a causa da doença e a prevenção" (U19); "Nesse ponto aí, os médicos e os enfermeiros pode explicar na hora de fazer os exames, porque na hora de fazer os exames eles terminam de anotar ali e não têm muito tempo, não. Deveria ter uma pessoa que pudesse esclarecer pra gente" (U20).

Para Colinvaux (2005), os contextos são determinantes de nossas condutas, ou seja, nos comportamos de maneiras diferentes se estamos na praia ou no teatro, em um restaurante ou nos bancos da escola. Pode-se dizer, então, que 
os contextos nos dizem, por mensagens silenciosas, o que se espera de cada um de nós. Nesse caso, se "as ações humanas são, sempre, ações mediadas por um contexto", o fato de os postos de saúde não implementarem um trabalho sistemático de divulgação ou de explicação sobre os conteúdos dos cartazes representa a mensagem silenciosa de inibição a aqueles que desejariam questionar ou ouvir uma explicação sobre os conteúdos expostos ou sobre outros assuntos referentes à área da saúde. É nesse sentido que o contexto dos postos de saúde desfavorece, mas não interrompe completamente, como veremos a seguir, a viabilidade do ensino informal em Ciências.

Ao lado desse aspecto desfavorável, a ausência de um trabalho sistemático, e do aspecto favorável, o desejo de aprender observado nos exemplos anteriores, aparece o favorecimento caracterizado pelos objetos presentes no ambiente. Pensando nos objetos presentes nos museus e nas ferramentas culturais do contexto, Colinvaux (2005) afirma que esses objetos têm características ou padrões próprios que determinam como podem ser usados ou manipulados:

Dito de outro modo, o desenho de exposições, atividades e dispositivos parece convidar a determinadas ações, ou padrões de interação, e não outros. Complementarmente ao convite a certas ações, as ferramentas culturais ao mesmo tempo delimitam o universo de interações possíveis, privilegiando alguns modos de uso em detrimento de outros. Nesta linha de raciocínio, cabe argumentar que talvez devêssemos considerar que os visitantes 'aprendem a usar' o museu (COLINVAUX, 2005).

Conclui-se, com isso, que as características proativas dos cartazes e folhetos informativos disponíveis nos postos de saúde tornam-se convites para a leitura de conteúdos científicos breves, quase sempre complementados por ilustrações chamativas que, por sua vez, constituem-se como novos convites interativos numa direção para a aprendizagem de Ciências na área da Saúde. Nesse caso, a função dos cartazes e folhetos existe, é efetiva e apresenta eficiência potencial, mas é ineficaz por razões extrínsecas. A delimitação aparece no problema social dos usuários não escolarizados e em outros fatores, como veremos adiante.

\section{PERFIL DOS SUJEITOS-USUÁRIOS}

De maneira geral, os usuários do posto de saúde investigado possuem baixa ou nenhuma escolaridade. Esses dados foram levantados por intermédio de observações, conversas informais com usuários e por informações transmitidas por um funcionário que trabalhava no atendimento ao público. Considerando-se apenas os sujeitos entrevistados, dez se declararam sem escolarização, dois disseram que estudaram até a $3^{\text {a }}$ série do Ensino Fundamental, dois estudaram até a $4^{\text {a }}$ série do Ensino Fundamental, um concluiu o Ensino Fundamental, um estudou até a $2^{a}$ série do Ensino Médio, dois concluíram o Ensino Médio. Cada um dos demais estudou, respectivamente, até a $1^{\mathrm{a}}$ e a $5^{\mathrm{a}}$ séries do Ensino Fundamental (quadro 1). 
Quadro 1: Usuários entrevistados e o respectivo grau de escolaridade

\begin{tabular}{|l|l|l|l|l|l|l|l|l|l|l|l|l|l|l|l|l|l|l|l|}
\hline U01 & U02 & U03 & U04 & U05 & U06 & U07 & U08 & U09 & U10 & U11 & U12 & U13 & U14 & U15 & U16 & U17 & U18 & U19 & U20 \\
\hline S/E & S/E & 2EM & 1EF & S/E & 3EF & S/E & 3EF & S/E & S/E & 4EF & S/E & S/E & S/E & S/E & 5EF & 8EF & 3EM & 3EM & 4EF \\
\hline
\end{tabular}

Nota: A $2^{\mathrm{a}}$ linha apresenta a série e o nível de ensino (S/E: sem escolaridade; EF: Ensino Fundamental; EM: Ensino Médio).

A frequência pela procura dos serviços da instituição, expressada pelos sujeitos-usuários, variou entre menos de uma vez por ano e mais de duas vezes por ano (quadro 2). Os motivos alegados centralizaram-se nos exames laboratoriais (fezes, urina, sangue, etc.) e consultas médicas (preventivo ginecológico, oftalmológico, pré-natal, diabetes, etc.).

Quadro 2: Frequência dos sujeitos-usuários ao local

\begin{tabular}{|l|l|}
\hline Frequência Declarada & Número de Sujeitos \\
\hline Menos de 1 vez por ano & 4 \\
\hline 1 vez por ano & 7 \\
\hline 2 vezes por ano & 3 \\
\hline Mais de 2 vezes por ano & 6 \\
\hline
\end{tabular}

Por causa das especificidades entre postos de saúde e museus, talvez não coubesse nenhum tipo de comparação sobre os perfis de seus respectivos públicos. Afinal, são instituições e públicos que apresentam objetivos e características bem distintas. Não há uma ingenuidade de nossa parte de querer trabalhar para o deslocamento das funções de um para o outro ou coisa parecida, mas apenas de entender os dois tipos de instituição nos seus pontos de convergência sobre o evento do ensino informal de Ciências. Fica evidenciada a especificidade do posto de saúde como instituição prestadora de serviço voltada prioritariamente "para as atividades preventivas, sem prejuízo dos serviços assistenciais” (BRASIL, 1988), para um público de perfil bem delineado, diferentemente do que ocorre em museus e centros de Ciências. Feita a ressalva, demarcaremos alguns dos aspectos sobre esses perfis.

Falk e Dierking (1992) apresentam três tipos de motivações para visitar um museu, que também são relembradas por Almeida (2005): razões sociais e recreativas; razões educacionais; e razões 'reverenciais' (reverential reasons). Apesar de não aparecer em nossa pesquisa nenhuma dessas motivações, aparentemente pode parecer que a instituição de saúde não oferece serviços de informação ou comunicação aos seus usuários, pois eles notadamente buscam os serviços médicos ou laboratoriais. No entanto, uma das ações previstas pela Lei 8.080/1990, artigo $7^{\circ}$, inciso VI, é a "divulgação de informações quanto ao potencial dos serviços de saúde e sua utilização pelo usuário” (BRASIL, 1990). O Ministério da Saúde sabe que a comunicação é fundamental na prevenção de doenças e na promoção da saúde. No portal do Ministério da Saúde na internet aparecem algumas orientações aos 
postos de saúde e, até mesmo, propostas de ações, por via de outros meios, direcionadas à informação e ao esclarecimento da população. Um exemplo é o projeto "O que é que eu faço doutor?” (vide http://portal.saude.gov.br/portal/saude/area. cfm?id_area=156), que também poderia ser aproveitado no ambiente dos postos de saúde, na proposta de diversificação de estratégias (discutiremos isso mais adiante) que ampliaria as possibilidades de ocorrência do ensino informal. "O que é que eu faço doutor?" refere-se a um conjunto de vídeos com temas baseados na vida e nas dúvidas das pessoas. Segundo informações do Ministério da Saúde, esse projeto já atingiu um público estimado de 30 milhões de pessoas somente via televisão. Com os vídeos disponíveis na internet, esse alcance poderá ser ampliado.

Sobre a assiduidade aos museus, Hood (1983 apud ALMEIDA, 2005) estabeleceu três categorias de público: i) público frequentador, que o visita pelo menos três vezes ao ano; ii) público eventual, que realiza de uma a duas visitas anuais; iii) não público, que passa dois anos sem visitar. Em outra pesquisa, Edwards e colaboradores (1990 apud ALMEIDA, 2005) identificaram que "visitantes altamente envolvidos têm mais chances de ver uma série de benefícios de uma visita, como as oportunidades para aprender e para experimentar novos desafios". Por outro lado, aqueles "com pouco envolvimento têm maior probabilidade de perceber a visita como uma experiência recreativa e dar grande valor a fatores sociais, como a chance de a família estar junta”. Pelo exposto no quadro anterior (quadro 2), vemos que uma parcela significativa dos sujeitos-usuários disse frequentar o local duas ou mais vezes por ano. A triangulação de nossos dados, no entanto, não foi conclusiva sobre a relação entre o grau de envolvimento (hábitos de leitura ou procura por explicações) e a frequência ao local. É caso para novos estudos, mas esse índice isolado de frequência dos sujeitos-usuários não pode ser considerado, $a$ priori, negativo para o ensino informal, pois as repetidas idas ao mesmo local ampliam as possibilidades de interação social que o contexto do ambiente promove.

Por último, mas ressaltando o alerta de Falk e Dierking (1992) sobre os cuidados na interpretação de dados do perfil de público de museus, Almeida (2005) aponta para a tendência de alta escolaridade e alto padrão socioeconômico na caracterização dos visitantes dos museus, excetuando-se alguns casos como o zoológico ou alguns centros de Ciências. Tomando-se apenas a qualidade do ensino informal na proposta de convergência entre as instituições, esse contraste de perfil apresenta-se como entrave para o ambiente do posto de saúde. Mas, ainda assim, como veremos adiante, não exclui a ocorrência.

\section{OBSERVAĈ̣̃O DOS CARTAZES E HÁBITO DE LEITURA}

As observações realizadas previamente forneceram indícios de que os usuários não leem os materiais expostos, o que motivou uma das perguntas da entrevista: "Quando está no posto de saúde, tem o costume de ler (ou olhar) os cartazes das paredes e folhetos entregues (ou a disposição no balcão)? Por quê?”. 
Podemos dizer que há uma efetividade dos cartazes e folhetos, porque existem e estão expostos ou disponibilizados. Sobre a eficiência deles, diante de suas características e objetivos, podemos dizer que apresentam informações ou conteúdos científicos significativos, ainda que, por vezes, sejam informações parciais ,característica que pode ser observada nas reclamações dos próprios leitores leigos: "Eu acho interessante porque informa como prevenir, agora este daqui da rubéola, que pega quando a mulher tá grávida, eu não sei se a prevenção é antes ou depois que a mulher tá grávida" (U18); "Eu acho que os cartaz não explica tudo, não" (U06). Entretanto, levando-se em consideração apenas os dados coletados e organizados no quadro a seguir (quadro 3), a eficácia dos cartazes e folhetos para o ensino informal não é plena, pois o hábito de leitura ou observação atinge apenas parcialmente os usuários:

Quadro 3: Leitura ou observação dos materiais e as justificativas

\begin{tabular}{|c|c|}
\hline $\begin{array}{l}\text { Hábito de leitura } \\
\text { ou de observação }\end{array}$ & Justificativa \\
\hline U01: Não & “Porque eu não sei ler". \\
\hline U02: Não & “Não sei ler". \\
\hline U03: Sim & "Informativos [pausa], as pessoas devem seguir as instruções". \\
\hline U04: Sim & $\begin{array}{l}\text { “Tenho sim, são bons. [Entrevistador: Por quê?] Nos ensina a previnir } \\
\text { várias coisas”. }\end{array}$ \\
\hline U05: Sim & “Porque eu não sei ler”. \\
\hline U06: Não & $\begin{array}{l}\text { "Nunca me interessei”. [Entrevistador: Por quê?] Eu acho que os cartaz não } \\
\text { explica tudo não". }\end{array}$ \\
\hline U07: Não & $\begin{array}{l}\text { "Olho, mas não entendo nada". } \\
\text { [sem escolarização] }\end{array}$ \\
\hline U08: Sim & "Vejo, eu leio, sim. São muitos informativos". \\
\hline U09: Sim & “Não, porque eu não sei ler e quem não sabe ler é cego, né?”. \\
\hline U10: Não & “Eu sempre olho. Mas não entendo, porque não sei ler". \\
\hline U11: Sim & $\begin{array}{l}\text { “Ó filha, geralmente eu não leio não, porque eu venho em quase na hora } \\
\text { de fazer a consulta. Nunca parei para ler, e aqui eu nunca vi uma pessoa } \\
\text { parada em frente ao cartaz, pergunta aos funcionários". }\end{array}$ \\
\hline U12: Não & "Porque não sei a leitura". \\
\hline U13: Não & $\begin{array}{l}\text { "Porque eu não sei ler. Mas, às vezes, quando eu tô com a minha neta, ela } \\
\text { lê para mim. E ai eu entendo o que ela lê". }\end{array}$ \\
\hline U14: Não & "Porque não sei ler". \\
\hline U15: Não & $\begin{array}{l}\text { Não. [Entrevistador: Por quê?] “Não sei responder, não, minha filha. Às vezes, eu } \\
\text { fico olhando as figura e me dá contade de saber o que é”. [sem escolarização] }\end{array}$ \\
\hline U16: Não & “Porque não dá tempo. Eu já chego em cima da hora de fazer o exame”. \\
\hline U17: Não & "Importante pra gente conhecer as doenças". \\
\hline U18: Sim & “Prevenção, né?" \\
\hline U19: Sim & "Têm informações". \\
\hline U20: Sim & "Por causa das prevenções". \\
\hline
\end{tabular}


Como se vê, as justificativas foram variadas, mas refletem o perfil de baixa ou nenhuma escolarização dos sujeitos, o que se transforma num entrave de partida para a eficácia dos cartazes e folhetos e, por consequência, de sua potencialidade para o ensino informal. Ainda assim, esses relatos são exemplos do efeito provocativo que esses objetos promovem no que diz respeito a outras possibilidades de interação: "Olho, mas não entendo nada" (U07); "Eu sempre olho. Mas não entendo nada porque não sei ler" (U10); "Porque eu não sei ler. Mas, às vezes, quando eu tô com minha neta, ela lê pra mim. E ai eu entendo o que ela lê" (U13); "Às vezes, eu fico olhando as figura e me dá vontade de saber o que é" (U15). O fator "sem escolarização" foi inibidor, mas não foi impeditivo para a observação dos materiais e a tentativa de compreendê-los. Em alguns casos, como vimos acima e ainda veremos mais adiante, percebemos que houve uma vontade explícita ou uma busca implícita de interação social a guiar-se para a zona de desenvolvimento imediato que poderiam ser levadas em consideração como estratégias mais diversificadas no contexto do ambiente.

Como afirma Gaspar (1993, p. 81) ao referir-se à interação social dirigida à zona de desenvolvimento imediato, "o professor, adulto ou parceiro mais capaz tem, implicitamente, um papel de orientação ou direção, já que é ele quem tem a consciência do objetivo da tarefa, demonstração ou conceito que está sendo trabalhado". O ponto de partida dessa interação, no entanto, está na situação criada "a partir da representação que cada participante faz do objeto dessa interação". Nesse caso, "na medida em que essa definição de situação por parte dos aprendizes seja mais homogênea, pode-se afirmar que essa interação será, não só viável, como mais produtiva".

Há alguns estudos que demonstram a importância do contexto social promovido pela situação de visitação aos museus e centros de Ciências, favorecendo a aprendizagem nesses locais de ensino informal em razão das interações, por exemplo, entre pais e filhos ou pessoas de idades, experiências de vida e graus de escolaridade diferentes. Lembrando-se de comentários de Robert Semper, diretor do Exploratorium de São Francisco, nos Estados Unidos, Gaspar (1993, p. 72) enfatiza que a experiência de aprendizagem no museu insere-se num contexto social porque as pessoas interagem com amigos, famílias, colegas e outros visitantes. Esses agrupamentos sociais incluem pessoas de idades, experiências e "backgrounds" diferentes.

O ensino ocorre como um aspecto fundamental dessas interações espontâneas entre familiares nos museus de Ciências. As interações são como um auxílio à aprendizagem, "servindo para tornar mais acessíveis tanto o feedback sensorial dos objetos e fenômenos apresentados nas exposições, como a informação simbólica (escrita ou figurativa) dos cartazes" (GASPAR, 1993, p. 73).

Se as afirmações anteriores refletem um aspecto de ensino informal promovido pela situação de visitação em museus e centros de Ciências, parece exequível que se faça uma aproximação dessas possibilidades também para os ambientes dos postos de saúde. O caso da neta que auxilia a avó no entendimento do conteúdo por intermédio da leitura insere-se num processo similar de ensino informal pela interação espontânea e afinidade familiar entre ambas: "[...] às vezes, quando eu tô com minha neta, ela lê pra mim. E aí eu entendo o que ela lê” (U13). 


\section{CARTAZES, FOLHETOS E AC̣ÕES PROVOCATIVAS DE APRENDIZAGEM}

Ao analisar a relação entre público e objeto nos museus, Almeida (2005) afirma que essa interação será facilitada quando as exposições forem desenhadas de acordo com a cultura do país ou região, "levando-se em conta o contexto pessoal dos visitantes, que está sempre embebido de sua experiência cultural".

Todos os objetos ou experimentos de um museu são projetados com o objetivo de transmitir algum tipo de informação ou conteúdo. Ocorre que nem sempre o planejamento e a implementação desses projetos seguem orientações culturais ou de alguma teoria pedagógica inerente ao contexto. "Às vezes ele [o projeto dos objetos] é desenvolvido através do processo pragmático-empírico da avaliação formativa, ou ainda é fruto apenas da experiência e intuição do seu criador" (GASPAR, 1993, p. 52). Os materiais impressos encaminhados aos postos de saúde pelos órgãos governamentais são elaborados com uma intenção bastante clara e exploram elementos chamativos ao seu público (ver quadro 4). Porém concordamos com o que Gaspar (1993) e Almeida (2005) pensam sobre os museus, e aplicamos esse modo de pensar também aos objetos dos postos de saúde, quando afirmam que os materiais poderiam ter melhor aproveitamento se por trás deles existissem desenho e bases teóricas inerentes e consolidadas ao contexto, o que excluiria, ou pelo menos minimizaria essa possibilidade de ocorrência: "Aprendi [com a leitura dos cartazes], mas ainda não ficou muito claro, não" (U06).

Quadro 4: Dados sobre a atenção despertada pelos cartazes e folhetos

\begin{tabular}{|c|c|c|}
\hline $\begin{array}{l}\text { Elementos que despertam a } \\
\text { atenção nos cartazes e folhetos }\end{array}$ & Frequência & Escolaridade dos usuários \\
\hline $\begin{array}{l}\text { Aspecto estético específico } \\
\text { ("figuras", "desenhos", “colorido") }\end{array}$ & 6 & $\begin{array}{l}\text { Um com } 4^{\circ} \text { EF e cinco } \\
\text { sem escolarização }\end{array}$ \\
\hline $\begin{array}{l}\text { Aspecto estético geral } \\
\text { ("são bonitos") }\end{array}$ & 1 & Sem escolarização \\
\hline $\begin{array}{l}\text { Aspecto de conteúdo } \\
\text { ("explicações, "informações sobre") }\end{array}$ & 9 & $\begin{array}{l}\text { Um sem escolarização; dois com } \\
3^{a} E F \text {; um com } 1^{a} E F \text { e um com } 2^{a} \\
E M \text {; dois com } 3^{a} E M ; \text { um com } 8^{a} \\
E F \text { e um com } 4^{a} E F\end{array}$ \\
\hline $\begin{array}{l}\text { Aspecto misto } \\
\text { (de conteúdo e estético) }\end{array}$ & 1 & $5^{\mathrm{a}} \mathrm{EF}$ \\
\hline $\begin{array}{l}\text { Nenhum aspecto } \\
\text { (“nada”, “não sei dizer") }\end{array}$ & 3 & Todos sem escolarização \\
\hline
\end{tabular}

Ao lado dos aspectos de conteúdo, os sujeitos-usuários também deram relevo ao que denominamos aqui de aspectos estéticos, ou seja, à inserção dos elementos ilustrativos dos materiais. Figuras, fotografias ou outros tipos de imagens entram no processo de interação dos sujeitos com os materiais, o que nos permite 
afirmar, tendo em vista a situação investigada, que são elementos que não podem ser descartados no processo de ensino informal, seja pela mensagem transmitida, seja pelo aspecto de motivação inicial ou impacto no leitor ou observador, que pode induzir a outros processos subsequentes de aprendizagem. A seguir, alguns excertos de relatos sobre os aspectos estéticos e de conteúdo dos cartazes e folhetos: "Através do retrato da imagem da doença, ajuda em alguma coisa, porque a pessoa que não sabe ler pode cuidar da doença através das informações. Eu quando era criança morava na roça, um deserto, e tive sarampo, catapora... e minha mãe cuidou da gente mesmo sem saber ler, porque via as outras pessoas doentes. Com as informações ela cuidou da gente" (U17); "As pessoas olham a figura e pode perguntar a outra pessoa. E também tem os agentes comunitários que tá sempre passando nas casas informando" (U18); "Ele não lê, mas o exemplo ali nas fotografias pode ajudar, até mesmo pode procurar saber o que eles vão olhar e procurar saber o que é isso que tá falando ali, e aquela pessoa que sabe ler pode explicar" (U20); “Com essas figuras ilustradas aqui, para as pessoas que não sabe ler, mas pode perceber aqui que tá falando do mosquito da dengue. E para as pessoas que não sabe ler, pode perguntar para as pessoas que têm aqui, que pode informar que tá falando da dengue e que pode ser evitado nas nossas casas" (U19); "Minha opinião, eu acho assim, é bom ter informativos, as pessoas devem seguir as instruções" (U03); "Nos ensina como prevenir várias coisas" (U04); "São bons para quem sabe ler, transmitem as informações aos pacientes" (U05); "São muito informativos” (U08).

Todos os elementos (tamanho, cor, figura, conteúdo, etc.) podem convergir para o objetivo de transmissão de conteúdo, mas parece que não alcançam plenamente esses objetivos diante das especificidades do público-alvo, o que pode ser indício da falta de uma teoria pedagógica ou epistemológica que auxilie o planejamento do material. Alguns relatos dos sujeitos-usuários do posto de saúde investigado tendem a dar sustentação a essa nossa suposição, um fenômeno que poderia ser explorado mais profundamente em outras pesquisas: "Às vezes, eu fico observando ali as figuras e fico imaginando que tipo de doença tem" (U01); "Não dá pra entender não, porque eu não sei ler. Se você não tivesse me explicado o que esses cartazes tá falando, eu não entenderia, não" (U01); "Sinto dificuldade, porque eu não sei a leitura" (U01); "Aprendi [com a leitura dos cartazes], mas ainda não ficou muito claro, não. Eu li uma vez sobre a hanseníase, mas ainda tenho dúvidas. Eu acho que os cartazes transmite, mas não explica tudo, não" (U06).

Relatos provenientes de usuários diferentes - coletados em momentos também diversos - convergiram para um ponto que nos permitiu fazer inferências que corroboram com as necessidades de dinamismo e de inserção de estratégias diversificadas para a ampliação das possibilidades do ensino informal nos postos de saúde. Três cartazes mostrados, dos quais fizemos indagações na segunda fase da entrevista, evidenciou-se um nítido direcionamento de olhar para o da dengue: "[Já aprendi] como prevenir a dengue" (U02); "Já aprendi a prevenir a dengue, não deixar mais pneus expostos no quintal... garrafas; não deixar água parada para evitar a dengue" (U03); "Ah, o da dengue... porque é o que mais a gente vê falar" 
(U05); "Esse aqui dá pra ver mais ou menos assim, que é pra manter o mosquito longe de casa, né? Pra evitar aquela doença... a dengue" (U15); "Ah, sim, eu não sei ler. Esses outros aqui mesmo eu não sei o que é não. Agora, esse é melhor... [apontou para o cartaz da dengue]. Todo dia eu escuto que é pra fazer isso, né, minha filha?" (U15); "Já aprendi a prevenir a dengue" (U04); "Gostaria de dizer que é muito interessante, porque tá chamando a atenção da nossa população sobre este mosquito invasor da dengue, que vem nos prejudicando há um bom tempo e que as pessoas que vem aqui no posto do [nome do bairro de localização do posto de saúde] não só venha, mas que leve para casa a mensagem, buscando sempre fazer as tarefas que aqui nos cartazes nos orienta. Então, que faça nas suas casas as suas tarefas e que também passe para o próximo, para os vizinhos e para as demais pessoas para se manterem informados sobre o mosquito da dengue. Pode ter onde ele fica alojado, como ele pode se reproduzir e quais os riscos que a gente tem e a maneira de evitar" (U19).

O que nos faz considerar sobre a necessidade de estratégias que não se prendam apenas na exposição estática dos cartazes e folhetos, fundamenta-se na demonstração de maior afinidade dos sujeitos-usuários ao fenômeno da dengue. Dentre os três conteúdos apresentados (rubéola, sarampo e dengue, conforme a figura 1 anteriormente apresentada), há uma maior exposição e exploração da da dengue na mídia. Nesse caso, cartazes e folhetos perdem em eficácia se comparados a outras formas de comunicação, como televisão e rádio, (seria interessante reformular esse trecho, que está muito confuso) que levam vantagens pela utilização associada com imagem e/ou áudio. Se as pessoas não param para ler os cartazes, não há interação, mas se as pessoas não param para ver as imagens do aparelho de televisão, a interação ainda assim pode ocorrer por intermédio do áudio. O áudio é, então, um elemento que amplia as possibilidades de interação entre sujeito e objeto, pois atinge, nível maior do que as palavras escritas, àqueles que não sabem ler: "Não, porque eu não sei ler e quem não sabe ler é cego, né?" (U09). Mas se não sabe ler, pode ouvir. Aliás, as ferramentas para essas ações existem e estão disponíveis no portal do Ministério da Saúde na internet, no projeto "Rádio Saúde" (vide http://portal.saude.gov.br/portal/saude/area.cfm?id_area=1302), que apresenta gravações em áudio sobre uma variedade de conteúdos da área. Por que, então, não potencializar o ambiente com todos os recursos já existentes?

$\mathrm{Na}$ proposta de traçarmos, neste estudo, um perfil de possibilidades de ensino informal nos postos de saúde, compreendido pelo embasamento da teoria vigotskiana, ainda pudemos resgatar nos relatos de nossos sujeitos elementos sobre a mediação semiótica, na tese de que o emprego específico ou funcional da palavra como meio de formação de conceitos é "momento central, que tem todos os fundamentos para ser considerado causa decorrente do amadurecimento de conceitos" (VIGOTSKI, 2001, p. 170), ou seja, a comunicação estabelecida por intermédio dos signos é relevante.

Observemos estes excertos: "É muito importante, porque é a prevenção, né? Ajuda a gente a prevenir e estar preparado para o surto” (U18); 
"Agora mesmo eu tava lendo sobre o problema da hanseníase. A maioria das informações são coisas do dia-a-dia. Agora, para aqueles que não sabe ler se torna difícil. Eu já aprendi as prevenções. A tuberculose, por exemplo, eu já sabia algumas coisas, mas com as faixas e os cartazes torna mais claro" (S08); "Uma vez eu li sobre a rubéola e aprendi como é que se pega" (U16); "É muito importante, porque a gente conhece mais as doenças... mais conhecimento. E a gente passa pra alguém que não tem conhecimento" (U17); "Eu li uma vez sobre a hanseníase” (U06); "Gostaria de dizer que é muito interessante, porque tá chamando a atenção da nossa população sobre esse mosquito invasor da dengue, que vem nos prejudicando há um bom tempo. É muito importante porque, às vezes, a gente vem aqui preocupado em marcar uma consulta e tem esses cartazes aí; e se a gente não tem alguma informação sobre o mosquito da dengue, esses cartazes aqui têm umas informações precisas para que a gente possa passar as informações no nosso bairro" (U19).

Há uma mescla de palavras ou conceitos (surto, prevenção, hanseníase, mosquito invasor, etc.) que se misturam nas falas e que transitam entre elementos de pseudoconceitos e conceitos, que mesmo sem o entendimento consciente por parte dos falantes, permite a comunicação deles. Já fazem parte do repertório os nomes das doenças e de alguns termos mais técnicos.

Entre os exemplos mencionados anteriormente, dois trechos chamaram atenção, cujas especificidades mereceriam, em outra oportunidade, maiores discussões: i) o uso dos signos para a construção de uma ideia antropocêntrica ("mosquito invasor"); ii) a potencialidade propagativa do emprego funcional das palavras apreendidas ou presentes no repertório ("a gente passa pra alguém que não tem conhecimento"; "aqui têm umas informações precisas para que a gente possa passar as informações no nosso bairro").

Por fim, a exposição analítica empreendida até aqui, e que não se esgota neste espaço restrito de artigo, pode subsidiar, juntamente com outros estudos similares, a compreensão sobre o ambiente informal no ensino de Ciências, cuja ocorrência, no caso específico, em um posto de saúde, apresenta limites (de fácil superação ou não), mas com tendência de favorecer o desenvolvimento cognitivo. As interações observadas, no mínimo, mobilizam a zona de desenvolvimento imediato e/ou provocam a ampliação do repertório de pseudoconceitos. Estes, por sua vez, mesmo que não sejam retomados ou ressignificados pelo ensino formal, poderão servir ao aprimoramento da função comunicativa ou a um maior entendimento que permita algumas tomadas de decisão do sujeito.

\section{CONSIDERACְÕES FINAIS}

Postos de saúde não são instituições que objetivam a divulgação científica ou o ensino de Ciências, mas não podem ser desconsiderados quando se fala em potenciais ambientes de ensino informal, especialmente na área da Saúde. 
No delineamento que inicialmente propusemos fazer sobre o ensino informal no ambiente dos postos de saúde, pudemos identificar, sob a luz da teoria vigotskiana, alguns elementos de similitude na analogia com museus e centros de Ciências. Esses elementos nos dão parâmetros para uma melhor compreensão e ampliação de potencialidades do ambiente para o ensino informal.

Apesar de suas diferenças e particularidades próprias, ambas as instituições oferecem condições para o desenvolvimento de interações sociais (sujeito-sujeito, sujeito-objeto e sujeito-contexto). Essas interações criam condições para o desenvolvimento cognitivo quando se dirigem à zona de desenvolvimento imediato. A depender de estratégias ou aprendizado de uso dessas ferramentas culturais, os objetos expostos, tanto em museus, como em postos de saúde, servem às possibilidades de ensino informal. Além das possibilidades de mediação semiótica e do aumento de repertório de signos que permitem avançar nas etapas do desenvolvimento, associa-se uma perspectiva de difusão desse repertório por intermédio de intenções propagativas espontâneas manifestadas pelos sujeitos.

No caso dos postos de saúde, a relevância do ensino informal aumenta na medida em que pode se constituir num dos poucos ambientes a oferecer acesso ao conhecimento científico básico estruturado, ainda que de forma incipiente, nesse precário processo de consolidação de cidadania pelo qual passa uma parcela significativa de nossa população.

\section{NOTAS}

${ }^{1}$ De acordo com Wagensberg (2005), há possibilidades que convergem em três tipos de interatividade nos museus: hands on (manipulação); minds on (reflexão) e heart on (emoção, sentimento).

${ }^{2}$ Optamos pelo uso da grafia Vigotski. As citações diretas seguem a grafia original dos autores.

${ }^{3}$ Ferramentas culturais são meios simbólicos e sistemas de significados diversos, como linguagem escrita e oral, instrumentos tecnológicos e ciência (COLINVAUX, 2005).

${ }^{4}$ Os cartazes foram cedidos pela Secretaria Municipal de Saúde e apresentavam as seguintes características: i) sarampo - $19 \mathrm{~cm}$ x $21 \mathrm{~cm}$, colorido, produzido pelo Ministério da Saúde; ii) rubéola - 14 cm x $20 \mathrm{~cm}$, colorido, produzido por meio de convênio entre a Secretaria Estadual de Saúde e o Ministério da Saúde; iii) dengue - $47 \mathrm{~cm}$ x $60 \mathrm{~cm}$; colorido, produzido pelo Ministério da Saúde.

\section{REFERÊNCIAS}

ALMEIDA, A. M. The personal context of a museum experience: similarities and differences between science and art museums. Hist. cienc. Saúde, Manguinhos, RJ, v. 12, supl. 0, p. 31-53, 2005. BIANCONI, M. L.; CARUSO, F. Educação não-formal. Ciência e Cultura, Campinas, v. 57, n. 4, p. 20-20, 2005.

BRASIL. Constituição (1988). Constituição da República Federativa do Brasil, 1988. Brasília, DF: Senado Federal, Centro Gráfico, 1988. 
BRASIL. Congresso Nacional. Lei 8.080, de 19 de setembro de 1990. Brasília, DF: Senado Federal, Centro Gráfico, 1990.

COLINVAUX, D. Science museums and psychology: interactivity, experimentation, and context. Hist. Cienc. Saúde, Manguinhos, Rio de Janeiro, v. 12, supl. 0, p. 79-91, 2005.

COOMBS, P. A crise mundial da educação. São Paulo: Perspectiva, 1986.

COOMBS, P.; AHMED, M. Attacking rural poverty: How now-formal education can help. New York: ICED, 1973.

FALK, J.; DIERKING, L. The museum experience. Washington: Whalesback Books, 1992.

GASPAR, A. Museus e centros de ciências: conceituação e proposta de um referencial teórico. 1993. 118 f. Tese (Doutorado em Educação) - Faculdade de Educação, Universidade de São Paulo, São Paulo, 1993.

GASPAR, A.; MONTEIRO, I. C. C. Atividades experimentais de demonstrações em sala de aula: uma análise segundo o referencial da teoria de Vigotski. Investigações em Ensino de Ciências, Porto Alegre, v. 10, n. 2, 2005.

GOHN, M. G. Educação não-formal na pedagogia social. In: CONGRESSO INTERNACIONAL DE PEDAGOGIA SOCIAL, 1., 2006, São Paulo. Proceedings online... São Paulo: Faculdade de Educação, USP, 2006. Disponível em: <http://www.proceedings.scielo.br/scielo.php?pid=MSC0 000000092006000100034\&script=sci_arttext>. Acesso em: 02 maio 2007.

MARANDINO, M. Interfaces na relação museu-escola. Cad.Cat.Ens.Fís., Florianópolis, v. 18, n.1, p.85-100, abr. 2001.

RODRIGUES, A; MARTINS, I. P. Ambientes de ensino não-formal de ciências: impacte nas práticas de professores do $1^{\circ}$ ciclo do ensino básico. Enseñanza de las Ciencias, Barcelona, número extra, 2005.

VIGOTSKI, L. S. A construção do pensamento e da linguagem. São Paulo: Martins Fontes, 2001

WAGENSBERG, J. O museu total, uma ferramenta para a mudança social. In: CONGRESSO MUNDIAL DE CENTROS DE CIÊNCIAS, 4., 2005, Rio de Janeiro, Textos provocativos... Rio de Janeiro: Fiocruz, 2005.

WERTSCH, J. Mediated action. In: BECHTEL, W.; GRAHAM, G. (eds.). A companion to cognitive science. Oxford: Blackwell, 1999, p. 518-525.

Data do Recebimento: 27/01/2011

Data de Aprovação: 09/10/2011

Data da Versão Final: 14/03/2012 